\title{
O PROFESSOR COMO GERENTE: RELATO DE UMA EXPERIÊNCIA ÉTICA EM SALA DE AULA
}

\section{Roberto Patrus Mundim Pena}

\section{RESUMO}

O problema da disciplina em sala de aula é um fenômeno presente nas escolas desde o ensino fundamental até o ensino superior. As recomendações para a criação e a manutenção de um ambiente de aprendizagem, baseado no respeito e na vontade de aprender, não passam, em geral, de um plano de intenções abstratas, ainda que permitam o levantamento de ricas reflexões sobre as causas e as diversas dimensões do fenômeno. Nos cursos superiores de Administração, a questão ganha maior relevância, pois se um professor não consegue administrar a sua sala de aula, qual o exemplo que está dando para a administração de uma empresa ou de um setor dela? Este artigo tem o propósito de descrever uma experiência bem sucedida para resolver o problema da disciplina em sala de aula nos cursos de Administração de um Centro Universitário privado de Minas Gerais. A iniciativa coube ao professor da disciplina de Filosofia e Ética, com apoio das Coordenações dos Cursos. O problema da (in)disciplina é contextualizado teoricamente a partir de seis variáveis: ética, antropológica, política, psicológica, tecnológica e gerencial. Tais variáveis são reunidas no conceito de função gerencial, compreendido como a capacidade do gerente de administrar, com competência técnica, política e pessoal, os conflitos presentes nas relações interpessoais de um grupo de trabalho, como a sala de aula. Os pressupostos teóricos embasaram a implementação, pelo professor, de um conjunto de regras estabelecidas no primeiro dia de aula. Os resultados apontaram para a resolução dos problemas de indisciplina, melhor aproveitamento do tempo das aulas e aumento da satisfação dos alunos e do professor com a qualidade das aulas. O artigo oferece informações para que o procedimento seja repetido por outros professores e sugere que a administração dos conflitos em sala de aula constitui-se no primeiro testemunho que o aluno tem da capacidade gerencial do seu professor.

\section{INTRODUÇÃO}

O problema da disciplina em sala de aula é um fenômeno presente nas escolas desde o ensino fundamental até o ensino superior. Apesar do tema ser objeto de artigos e reflexões no meio acadêmico, o problema está longe de ser considerado resolvido e as reuniões de professores acabam por tornar-se repetitivas, ano após ano, na discussão do assunto. As recomendações para a criação e a manutenção de um ambiente de aprendizagem, baseado no respeito e na vontade de aprender, não passam, em geral, de um plano de intenções abstratas, com instruções genéricas que impedem a transformação da prática docente e discente, ainda que permitam o levantamento de ricas reflexões sobre as causas e as diversas dimensões do fenômeno. Nos cursos superiores de Administração, a questão ganha maior relevância, pois se um professor não consegue administrar a sua sala de aula, qual o exemplo que está dando para a administração de uma empresa ou de um setor dela?

Este artigo tem o propósito de descrever uma experiência bem sucedida para resolver o problema da disciplina em sala de aula nos cursos de Administração e de Turismo e Gestão em Hotelaria, da Faculdade de Ciências Administrativas e Contábeis de um Centro Universitário privado de Minas Gerais. A iniciativa coube ao professor da disciplina de Filosofia e Ética, com apoio das Coordenações dos Cursos. O conteúdo deste trabalho está dividido em 4 partes. A primeira apresenta o problema. A segunda parte faz a contextualização teórica do problema a partir de suas variáveis constituintes. A terceira parte relata a experiência de um professor de Filosofia e Ética nos cursos de Administração e Turismo, com o propósito de resolver o problema da indisciplina em sala 
de aula. A quarta parte trata da conclusão.

\section{1- O PROBLEMA}

A indisciplina é a ausência de disciplina. A disciplina diz respeito à regulamentação das "condutas dos diversos membros de uma coletividade, imposto ou aceito democraticamente, que tem por finalidade o bem estar dos membros e o bom andamento dos trabalhos" (HOUAISS, p.1052). A origem etimológica do termo, do latim, disciplina, discere, nos remete à "ação de se instruir, educação", ou simplesmente "aprender". O problema da (in)disciplina, implica, portanto, nas seguintes considerações:

$\left.1^{\mathrm{a}}\right)$ Trata-se de um problema que envolve a coletividade. Como tal, pertence ao âmbito da ética, isto é, implica na investigação da conveniência das condutas de um indivíduo ou grupo e das suas repercussões sobre a comunidade onde este indivíduo ou grupo se insere.

$2^{a}$ ) A disciplina diz respeito à educação. $O$ termo indisciplina é sinônimo de falta de educação. A educação, entendida como a arte de ensinar às pessoas o conhecimento necessário para sobreviver e viver em sociedade, consiste na transmissão, sistematizada ou não, dos conhecimentos e valores construídos pela humanidade ao longo dos tempos. Tem duas dimensões interdependentes: a informação e a formação. A informação é o conhecimento de que todos precisam estar de posse para sobreviver e para bem viver, com saúde, felicidade, civilidade, respeito ao próximo, poder, independência e amor. A formação é a reflexão sobre a informação, pois esta precisa ser atualizada e contextualizada continuamente.

$3^{\mathrm{a}}$ ) A disciplina pode ser imposta ou pactuada democraticamente. Se imposta, podemos dizer que o controle sobre a conduta é externo. Se combinada democraticamente, significa que o regulamento é objeto de um contrato do sujeito com os seus semelhantes.

Neste artigo, entendemos a indisciplina em sala de aula, como uma conduta mal-educada que compromete o bem estar dos membros do grupo e o bom andamento das aulas. Compreendida como um ato de mal-educação, a indisciplina pode manifestar-se tanto por palavras como por atitudes. A disciplina, por sua vez, é compreendida no âmbito da mediação entre os dois termos do par dialético "natureza e cultura", como será explicitado adiante quando da descrição da variável educativa. O problema da disciplina será tratado, pois, dentro de um contexto educativo, compreendido teoricamente no âmbito da mediação entre natureza e cultura, isto é, como um mediador da humanização do ser humano, tal qual o trabalho. Isso significa dizer que a disciplina é um elemento fundamental no processo de humanização do ser, tendo, portanto, implicações éticas relevantes, no contexto da vida em sociedade. A nível pragmático, enfocaremos a disciplina no âmbito da sala de aula, mais especificamente no universo do ensino superior, nos cursos de gestão, como o de Administração e o de Turismo e Gestão em Hotelaria.

\section{2- CONTEXTUALIZAÇÃO TEÓRICA DO PROBLEMA}

O problema da indisciplina em sala de aula não é um problema de natureza exclusivamente pedagógica. A escola está inserida em uma sociedade e relaciona-se dialeticamente com ela. Neste artigo, procuramos contextualizar a questão a partir de diferentes variáveis, de modo a ampliar a compreensão do fenômeno e preparar as bases teóricas da intervenção prática que foi feita em sala de aula e que descrevemos no capítulo seguinte. Estas variáveis estão interligadas umas às outras, e a divisão feita aqui obedece a uma pretensão didática no sentido de enumerar as diversas facetas do problema. 


\subsection{A VARIÁVEL ÉTICA}

A questão da indisciplina em sala de aula é um problema ético. A ética é a reflexão sobre o que convém, sobre o que é bom. Ao investigar o que proporciona o viver bem, duas dimensões estão presentes: a individual e a social. Se a reflexão ética enfatizar o indivíduo, vai investigar os valores e critérios que levam o sujeito a escolher uma conduta, considerada boa, em detrimento de outra. Se, por outro lado, a reflexão ética enfatizar a sua dimensão social, ela vai refletir sobre os costumes de um determinado grupo e sua razão de ser naquele determinado momento histórico (PENA, 2000). O costume é o resultado da repetição de condutas que se padronizaram. Uma vez estabelecido socialmente, ele tende a condicionar o comportamento individual. Essas duas dimensões da ética, a individual e a social, estão, portanto, interligadas. Uma não existe sem a outra, embora o estudo da ética possa enfatizar uma ou outra.

Os costumes de um grupo, os seus mores, representam a sua moral, ou seja, o conjunto de condutas esperadas por um grupo social em um dado momento histórico. Não raramente, a ética é definida como a ciência da moral, isto é, como um campo do saber cujo objeto de investigação é a razão de ser dos costumes de um grupo. Quando a moral de uma sociedade é uniforme e sua influência sobre o comportamento dos indivíduos é exercida de forma hegemônica, os significados de ética e moral se confundem porque as razões de considerar-se algo correto (ético) coincidem com o comportamento ao qual a sociedade está acostumada (moral). Nesse contexto, na prática, o que é ético também é moral e o que é moral também é considerado ético, apesar dos dois termos terem significados diferentes.

Quando os costumes não conseguem impor a força da sua tradição sobre o comportamento dos indivíduos e estes passam a agir de modo diferente do que fora estabelecido como moral, como padrão, podemos falar em um momento de crise moral, pois os costumes sociais já não obedecem aos critérios até então usados para o estabelecimento das condutas corretas. No momento de crise, o que é correto (ético) para alguns pode ser imoral (contra os costumes) para outros. Quando a reflexão sobre o que é bom ou certo leva à valorização de uma conduta que em tempos anteriores seria imoral, vive-se um momento de crise, que pode preparar a transição para um novo padrão de comportamento social, para uma nova moral. Estamos vivendo justamente este momento. Isso faz com que o tema da ética ganhe relevância e a educação apareça como fator fundamental no sentido de acelerar a transição para uma nova ordem moral.

\subsection{A VARIÁVEL EDUCATIVA}

O ser humano, ao contrário dos animais, não é o seu corpo, ele tem o seu corpo (ALVES, 1990). A consciência de seus instintos lhe permite controlá-los e criar um mundo diferente do mundo dado, da natureza. O mundo da cultura, produção humana, estabelece uma ruptura com o mundo da natureza, reprodução biológica, porque não repete uma programação hereditária, mas inventa uma forma de viver inteligente e criativa. A disciplina, como mediadora entre natureza e cultura, é trabalho, pois implica na transformação da conduta impulsiva em conduta inteligente. Nessa perspectiva, o trabalho de disciplinar-se é um trabalho educativo. Educar é transformar a natureza humana em produto da cultura, daí a sua vocação originariamente humanista e a sua ligação íntima com a ética.

A relação entre ética e educação é, pois, inequívoca, pois ninguém nasce sabendo o que lhe convém. Esse saber viver precisa ser ensinado aos seres humanos. E precisa ser atualizado, contextualizado e adaptado às transformações históricas. É necessário informar e formar, instruir e refletir, transmitir conhecimentos e criticá-los. Esse papel da educação ganha importância diante da atual crise dos 
costumes ou crise moral, que se revela, na escola, como indisciplina ou falta de educação.

A falta de educação é o flagrante desrespeito às normas de boa convivência social. Implica em alguma falha no processo educativo, seja na transmissão dos conhecimentos e valores (informação), seja na reflexão sobre esses conhecimentos e valores (formação). A primeira instituição cultural responsável pela educação dos indivíduos é a família. A segunda é a escola. A falta de educação tem as suas raízes, portanto, na crise da família e repercute na instituição escolar.

A família como instituição social, célula básica da sociedade, cada vez mais se privatiza, deixando de ser espaço de educação para a vida pública. O aprendizado da vida em sociedade, e até de um ofício, é transferido para a escola. A família torna-se puramente privada, deixando de ser plenamente educativa, pois, como vimos, o papel da educação é transmitir os conhecimentos e valores acumulados pela cultura e fazer deles objeto de reflexão.

No âmbito da família, a autoridade dos pais entra em crise. No contexto rural, há algumas décadas, os pais eram autoritários tanto por necessidade quanto por costume (ÁRIES; DUBY, 1992). Se o feijão estivesse secando no terreiro da casa e o céu se fechasse, com ameaça de chuva, a ordem dos pais para recolher o feijão era obedecida imediatamente, pois, o contrário representaria prejuízo e dificuldades para toda a família. Hoje, nos centros urbanos, a autoridade dos pais deixa de relacionar-se com tarefas familiares indiscutíveis e se torna arbitrária. Quando o pai pede ao filho para desligar a televisão e ir dormir porque já está tarde da noite, o filho responde para o pai não se estressar, porque se ele ficar com sono no dia seguinte, o problema é dele. Se o filho não ajudasse a proteger a colheita do feijão da chuva que se aproxima, o prejuízo seria coletivo, de toda a família. Mas se o jovem filho dorme mais tarde e fica sonolento no dia seguinte, o prejuízo é individual.

Em síntese, a família perde o seu caráter social e se privatiza. Esta afirmativa pode ser ilustrada com uma expressão curiosa, muitas vezes ditas na escola ou no trabalho: comporte-se, porque você não está na sua casa! Essa frase sugere que, em casa, o indivíduo pode fazer o que bem entender. O lar deixou de ser um espaço de educação para a vida em sociedade para se converter em um espaço de liberdade privada e individual, onde o indivíduo se comporta como bem entender, sem dever satisfação a ninguém. A primeira causa para o problema da falta de educação e para a indisciplina em sala de aula está relacionada, portanto com a privatização da família. Se antigamente, como sugerem Ariès e Duby (1992), a família passava na frente do indivíduo e controlava a sua vida privada (correspondência, amizades, profissão e até casamento), atualmente, principalmente nos grandes centros urbanos, o indivíduo passa na frente da família. Antes, o indivíduo era julgado em função da contribuição que prestava à sua família. Agora, a família é julgada em função da contribuição que oferece à vida privada individual.

Esta transição no papel da família fica muito clara quando se ouve uma outra expressão dita por um pai ou uma mãe a seu filho: Você está achando que aqui é hotel? Para o pai, o filho deve servir à família. Para o filho, a família deve servi-lo. O hotel serve a seu hóspede, está a seu serviço. A geração de nossos pais, ou de nossos avós, considera um absurdo que o filho usufrua o lar como quem desfruta de um hotel. Para eles, o filho deveria se comportar com a cerimônia de uma visita, de um hóspede, pois, enquanto ele não se sustentar, deve obedecer às regras da casa.

A conseqüência da privatização da família é a transferência do papel de educar para a escola. Cada vez mais cedo, as crianças são inseridas na instituição escolar. A escola passa a ter uma 
responsabilidade ainda maior na tarefa de educação de seus alunos para a vida em sociedade e para a sua formação ética. A escola, enfim, torna-se a principal instituição responsável pela transmissão dos valores e conhecimentos da cultura.

\subsection{A VARIÁVEL POLÍTICA}

O conceito de autoridade vem sido confundido com o conceito de autoritarismo. Esse equívoco vem impedindo o professor de usar de sua autoridade em sala de aula, como medo de ser considerado autoritário. A autoridade é o direito ou o poder de se fazer obedecer, de tomar decisões. Na sala de aula, reconhecemos, no professor, o direito e o poder de criar e manter um clima adequado para o processo de aprendizagem. Isso significa que o professor tem o poder de se fazer obedecer por seus alunos. A íntima relação entre autoridade e poder parece ter dificultado uma melhor compreensão da autoridade do professor em sala de aula, pois o uso do poder é, muitas vezes, tido como eticamente suspeito (Siqueira et alli, 1992). Segundo Crozier (1981), "o problema do poder sempre constituiu um problema difícil para a teoria das organizações" (p. 211), sendo que a sua importância somente foi reconhecida nos estudos sobre as organizações a partir da década de 60. Atualmente, reconhece-se, efetivamente, que "a distribuição do poder e o sistema das relações de poder no seio de uma organização têm uma influência decisiva sobre as possibilidades e as formas de adaptação de cada um dos seus membros, e sobre a eficácia do conjunto da organização" (Crozier, 1981, p. 215).

Se a autoridade confere o direito e o poder de se fazer obedecer, é necessário compreender o que seja o poder e distingui-lo do conceito de força. Poder (do latim, potentia) é ter a faculdade de, é ter a capacidade de influenciar o comportamento de uma pessoa ou grupo. A força, por sua vez, é o uso de um procedimento de coerção com o propósito de promover o movimento desejado, isto é, de alterar o estado das coisas. A autoridade confere poder a quem a possui para usar a força com o fim de influenciar ou punir o comportamento de outrem. A força é um recurso estratégico para fazer valer a autoridade. Ter poder não significa necessariamente usar a força. Ter poder significa ter a capacidade de fazer uso da força, se necessário. Quem é ou detém a autoridade não só pode fazer uso da força, mas também tem o direito de fazer uso dela. Quando a força é usada de modo legítimo, isto é, quando ela é conferida por uma autoridade estabelecida ou compactuada, estamos a falar de autoridade. Quando, por outro lado, a força é usada de forma arbitrária, sem legitimidade, estamos a falar de autoritarismo.

A diferença entre autoridade e autoritarismo pode ser mais bem compreendida a partir do exemplo seguinte. Um guarda de trânsito tem autoridade para multar o motorista que avança o sinal vermelho e, se o faz, o uso da força (a multa) é legítimo. No entanto, se o guarda multa um motorista que não cometeu nenhuma infração, podemos dizer que ele está sendo autoritário. O uso da autoridade, observados os direitos e deveres estabelecidos no contrato, não é antiético, é lícito e necessário para se viver em sociedade. $\mathrm{O}$ esclarecimento deste equívoco na compreensão do poder contribui para explicar a falta de discernimento entre autoridade e autoritarismo, verificada, por exemplo, na atuação de alguns gerentes e professores.

Supondo que as regras que regem o trabalho de uma empresa tenham sido estabelecidas para garantir os interesses da organização como um todo, analisemos o comportamento de um gerente. Imaginemos que ele se sinta constrangido de chamar a atenção de seus subordinados e evite corrigir as suas falhas. $\mathrm{O}$ gerente não deseja ser autoritário, muito menos ter a má fama de sê-lo. Como autoridade, ele tem o poder de coibir as transgressões às normas, estabelecidas para que o trabalho seja eficiente. Mas, ao agir de modo relaxado, ele contribui para que a sua autoridade, conferida pela instituição, não seja reconhecida. Quando isso acontece, corre-se o risco de que os interesses 
particulares dos indivíduos que compõem o grupo prevaleçam sobre os interesses coletivos, que o chefe representa, comprometendo a própria razão de ser da organização. Neste caso, o eventual fracasso poderia ser atribuído ao equívoco do gerente de ter considerado poder como coerção. Ao negar esta, ele negou aquele: temendo parecer autoritário, ele negou a sua autoridade, conferida para preservar os interesses comuns do grupo.

O mesmo fenômeno pode ser observado em uma organização escolar. A escola, em geral, confere ao professor autoridade para que ele regule os conflitos em sala de aula e proporcione um ambiente adequado para a aprendizagem. Cabe ao professor, portanto, (e os alunos geralmente exigem isto dele), usar de seu poder para que haja disciplina e condições favoráveis de ensino - aprendizagem. Se o professor não reconhece esse direito como legítimo, por confundir poder com força, ele será incapaz de administrar os conflitos no interior de sua classe. Do mesmo modo, se ele exagera no uso de seu direito de se fazer obedecido, isto é, se usa a força indiscriminadamente, mesmo quando não é necessária, ele está se fazendo autoritário. O autoritarismo associa o poder ao uso indiscriminado da força, e, como já foi dito, o poder não implica, necessariamente, no uso da força, mas na faculdade potencial de usá-la. Em ambos os casos, seja o do professor lassez-faire, seja o do professor autoritário, confunde-se poder com força.

A partir dos exemplos, fica claro que é o poder que institui a possibilidade da vida humana associada (Gomes, 1993). Enquanto o poder só existe quando os homens convivem em grupo, a força é a qualidade natural do homem isolado (Arendt, 1991). Em síntese, o poder é legítimo como faculdade potencial para assegurar a observância às regras e leis - conditio sine qua non para a convivência em grupo - e inibir a transgressão. A força, ou o uso da coerção, é a arma com que a organização, o Estado, a escola, ou qualquer outra associação de pessoas reunidas com objetivos comuns, podem lançar mão para fazer cumprir as leis estabelecidas, espera-se, através do consenso.

Numa sala de aula, o professor é a autoridade. Cabe a ele fazer uso do seu direito e do seu poder de fazer-se obedecer por seus alunos. Do mesmo modo que o gerente é a autoridade em uma loja e o patrão é a autoridade em sua empresa, compete ao professor fazer uso da força, quando necessário, para garantir os propósitos de sua atividade educativa. Se o educador considera, por princípio, o uso da força como anti-ético, ele renuncia à sua autoridade como professor.

A partir da contribuição de Maquiavel, a ciência política aponta para a necessidade de que, em um contexto de crise, o chefe imponha a sua autoridade para fazer valer o seu poder. Parafraseando Brasil (1996), poderíamos falar em "medidas anti-anti-pedagógicas" para referir-se à necessidade do professor afirmar a sua autoridade em um contexto de crise e conflitos, no qual todos os participantes julgam poder fazer o querem, pois "não existe tribunal a que recorrer" (MAQUIAVEL, 1993, p. 103). Em um ambiente em que as atitudes são contrárias aos objetivos do grupo, cabe ao líder ter atitudes que coíbam e inibam tais atitudes, ou seja, cabe ao líder promover atitudes anti-anti-pedagógicas.

Em suma, o professor é autoridade em sala de aula, o que não significa que deva ser autoritário. Sabemos que o poder só existe em uma relação. Ele só é exercido por uma parte se quem o sofre o reconhece como tal. Nesse sentido, parece que os alunos têm demonstrado mais poder do que os professores, uma vez que estes se sentem absolutamente impotentes diante dos alunos, tornando-se influenciados pela aparente falta de compromisso dos alunos com a sua aprendizagem. Considerando que a relação professor-aluno confere ao professor uma autoridade moral, no sentido de ser reconhecido como o responsável pela condução do processo educativo, urge que os professores assumam a sua autoridade de mestres e educadores, com o propósito de promover as condições necessárias para o bem estar de todos e o bom andamento dos trabalhos acadêmicos. 


\subsection{A VARIÁVEL PSICOLÓGICA}

Segundo BRASIL (1996, p. 191), a moralidade é a busca da razão de ser da escolha de determinadas condutas em detrimento de outras. A autora aponta três níveis de moralidade. Cada nível corresponde a uma fase ontológica da evolução psíquica do ser humano.

A moralidade infantil é a da consciência espontânea, em que o indivíduo encontra-se à mercê dos prêmios e castigos de natureza concreta, material, objetiva. Não conseguindo se ver separado dos demais, o indivíduo pauta sua conduta pelo condicionamento, e suas comparações e seus discernimentos se prendem, apenas, ao efeito produzido pelas suas atitudes: é eticamente mau aquilo que lhe traz a frustração temida. A interpretação pessoal do "dever ser" é completamente pervertida no sentido da constatação "do que é", do resultado obtido.

A moralidade adolescente é a dos albores da consciência reflexiva, quando o indivíduo, ensaiando a subjetividade, a vivência do eu-sujeito e mundo-objeto, revolta-se contra a dependência infantil, sem no entanto, conseguir romper a escravizante manipulação daqueles que detêm o poder sobre ele, quer legal, quer econômico, quer afetivo. A consciência reflexiva, nos seus primórdios, incita o indivíduo a rejeitar a dominação dos demais indivíduos; mas a verdadeira moralidade, a interpretação pessoal do "dever ser" (ética), altamente influenciada pela emoção e pela religião, exige dele um conhecimento, pelo menos relativo, da cultura.

A moralidade adulta é a da consciência reflexiva na sua floração, chegando à liberdade plena em decorrência do viver na consciência do absoluto. A consciência reflexiva, impelindo o indivíduo à experiência da separação eu-sujeito e mundo-objeto, permite-lhe julgar cada valor, por meio da comparação e do discernimento, e criar um sistema próprio de valores, uma auto regulação. Os dados culturais permitem ao indivíduo compreender o sentido da sua história e o sentido da história da humanidade na busca de valores. Ele vai formando sua moralidade à medida que consegue questionar as normas tradicionais, não por simples revolta contra a moralidade imposta, mas pela capacidade de pensar por si mesmo em termos gerais e críticos. A moralidade interessa não apenas ao particular, mas também ao social. O emprego da razão, levando à autonomia, considera, inclusive, o bem comum e permite a ampliação da consciência reflexiva até a plena consciência do absoluto. (BRASIL, 1996, p. 191-192)

Cada um destes três níveis de moralidade é subdividido em outros níveis. A evolução de um nível de moralidade para outro é seqüencial. Não é possível ter uma moralidade adulta sem ter passado por uma moralidade adolescente. Também não é possível ser uma criança, cronologicamente falando, e ter uma moralidade adulta, embora possa haver pequenos atrasos ou adiantamentos nas faixas de idade, considerados normais, ou grandes atrasos ou adiantamentos, considerados excepcionais. Não necessariamente a idade que um indivíduo tem corresponde ao nível de moralidade próprio para a idade, podendo haver fixações em fases anteriores.

Segundo Brasil, processo de evolução do ser humano abarca não só a moralidade, mas o campo vivencial, a percepção, a emoção, a inteligência, a consciência, a sexualidade e a religiosidade, isto é, todos os componentes da personalidade. Como o papel do professor não lhe permite fazer o papel do psicoterapeuta, no sentido de promover esta evolução, a nível global, cabe-lhe, pelo menos, conhecer as fases de evolução da moralidade para compreender a sua atuação como educador e principal responsável pela disciplina em sala de aula. 


\subsection{A VARIÁVEL TECNOLÓGICA}

A tecnologia moderna tem um papel absolutamente relevante no estudo da nossa cultura atual. Podemos dizer que vivemos em uma cultura digital, o que, literalmente, (do latim, digitus, dedo) quer dizer que o nosso acesso ao conhecimento, ao lazer, ao trabalho e à comunicação, por exemplo, se dá através dos dedos, isto é, do simples teclar, ou clicar. O computador, o telefone, os aparelhos eletrônicos em geral, funcionam, cada vez mais, a partir de um click. Rojas (1996) fala em cultura do zapping para designar a síndrome do controle remoto. Podemos levantar a hipótese de que estamos transportando para as relações humanas o modo como nos relacionamos com a tecnologia. Se o programa de televisão ficou desinteressante, click, mudo o canal. Do mesmo modo, se, em sala de aula, a fala do professor lhe parece desinteressante, o aluno se desliga do assunto tratado pelo professor e se distrai, seja conversando com um colega, seja fazendo outra coisa, seja simplesmente, conectando-se em outra freqüência, absorto em seus pensamentos.

A cultura do zapping pode levar os professores a buscar a atenção dos seus alunos como quem luta para obter uma boa audiência. As estratégias pedagógicas se transformam em estratégias de marketing utilizadas para seduzir o aluno e impedir que ele abandone a audiência e se sintonize na freqüência do concorrente. Recursos de oratória, brincadeiras, bom humor e uma boa performance como artista passam a ser valorizados pelos alunos, que, de algum modo, podem estar transferindo para o professor a responsabilidade de motivá-los para a aprendizagem. Outra forma de conquistar a fidelidade do aluno, para usar uma expressão da área de Marketing, é procurar fazer uso de estratégias de avaliação, seja com provas surpresas, seja com o uso mágico das palavras prova ou isso vale ponto, o que leva o aluno a (click!) desligar-se da sua distração e prestar atenção ao que o professor está falando.

Além da cultura do zapping, outro fator relevante que interfere no problema da disciplina em sala de aula, relacionado com a tecnologia moderna, é a democratização do uso do telefone celular. Em pesquisa informal realizada com os alunos de Administração do Centro Universitário onde se realizou a experiência objeto deste artigo, verificou-se que entre 80 e $88 \%$ dos alunos possuem o aparelho de telefonia móvel. Este índice introduz uma nova variável na prática docente. Ainda que a escola proíba o uso do aparelho em sala de aula, muitos alunos mantêm os seus telefones ligados, no modo silencioso ou no vibracall. Como, em geral, os alunos universitários podem sair e entrar na sala quando querem, o telefone celular passou a ser uma variável importante no entra-e-sai dos alunos, com prejuízo evidente da qualidade das aulas e do seu aproveitamento pelos alunos.

Em suma, vivemos em uma cultura digital. Seja teclando o controle remoto, seja clicando o teclado do telefone celular, a tecnologia é uma variável indiscutível no processo ensino-aprendizagem e na relação professor-aluno. Sua inserção no processo não aparece apenas como novas alternativas de recursos didáticos à disposição do professor, mas também como recursos disponíveis para os alunos e não necessariamente dirigidos para o processo de aprendizagem.

\subsection{A VARIÁVEL GERENCIAL}

Consideramos a variável gerencial como a necessidade da administração de um espaço (a sala de aula) e de pessoas (os alunos), em um ambiente organizacional (a escola). Compreendemos o professor como um gerente, responsável por esta administração, que presta um serviço a seus alunos, dentro de uma instituição escolar. $\mathrm{Na}$ atividade da sala de aula, estão presentes todas as variáveis apontadas anteriormente, sendo que o professor tem um papel gerencial relevante em cada uma delas. A sala de aula é um espaço ético, pois ali interagem os interesses individuais e coletivos, sendo que o professor é responsável em promover a reflexão sobre o que é melhor para o indivíduo e o que é melhor para o grupo, estabelecendo limites e demarcando direitos e deveres com os seus 
alunos. Trata-se, também, de um espaço de natureza antropológica, visto que a atividade educativa se insere na constante mediação entre o mundo da natureza e o mundo da cultura, sendo que o professor é responsável pela reflexão acerca da necessidade do contrato social para o estabelecimento de limites para a convivência coletiva com vistas ao viver bem e à humanização do ser. A variável tecnológica aparece refletida no espaço da sala de aula, à medida que o uso do aparelho celular precisa ser disciplinado pela instituição e controlado pelo professor. Além disso, como vimos, a cultura digital serve de metáfora para a compreensão da dificuldade de concentração dos alunos em atividades que demandam leitura e atenção por um pouco mais de tempo. Compreendemos a sala de aula como uma célula política, inserida em um tecido social mais amplo e marcada pela interação de pessoas com interesses diversos. O professor, como autoridade em sala, desempenha, pois, um papel de liderança política no sentido de influenciar os alunos para a realização dos objetivos do ensino. Finalmente, o nível de moralidade do professor vai determinar a sua capacidade de atuação em sala de aula, sendo que a moralidade do grupo será o resultado da interação entre o nível de moralidade de cada um dos líderes que este grupo venha a ter.

Sendo assim, consideramos que o ensino da administração encontra o seu exemplo mais prático, e, paradigmático, na administração que o professor faz da sua própria sala de aula. Acreditamos que, no espaço da sala de aula, sejam reproduzidos inúmeros conflitos e problemas vividos pelos gerentes em uma organização. Centramos nossa abordagem no professor por considerá-lo o membro do grupo revestido de autoridade pela instituição. Nessa perspectiva, apontamos algumas condições necessárias ao professor-gerente para o sucesso das iniciativas que aqui serão sugeridas para a resolução do problema da disciplina em sala de aula. São elas:

- $\quad$ Condição ética: ter consciência do seu papel de líder no estabelecimento do clima ético adequado para a aprendizagem.

- $\quad$ Condição educativa: ter consciência do seu papel de educador, no sentido de não se limitar a mero transmissor de informações, mas de promover o processo de humanização do aluno, através do testemunho de que a vida é trabalho, o que exige a transformação da natureza (ofício) e da própria natureza (autodisciplina).

- Condição política: ter respaldo da coordenação do curso e da diretoria ao implementar o seu projeto de gerenciamento da turma e de suas aulas.

- $\quad$ Condição psicológica: ser moralmente adulto, isto é, capaz de julgar cada valor, por meio da comparação e do discernimento, e criar um sistema próprio de valores, uma autoregulação. O adulto reconhece o impacto de suas intervenções no ambiente, está aberto para a reformulação de suas condutas, mas não teme a avaliação negativa, nem busca a avaliação positiva que possam fazer dele. Sabe que suas ações precisam estar fundamentadas em uma filosofia de vida própria, base para a aceitação da responsabilidade total de seus atos.

Condição tecnológica: ter domínio dos meios técnicos para transmissão do saber (didática), consciente de que vivemos em uma cultura da imagem, com a qual os jovens estão familiarizados.

A função gerencial exige a síntese de todas essas condições, que podem ser resumidas na capacidade do professor de ter e demonstrar competência técnica, competência política e competência pessoal. A competência técnica significa conhecer o conteúdo da sua disciplina e dominar a forma da transmissão do saber (didática). A competência política diz respeito à compreensão e capacidade de atuar como líder em sala, no sentido de promover a realização dos interesses comuns do grupo. A competência pessoal diz respeito à capacidade do professor de administrar seus próprios conflitos. Como se pode perceber, a função gerencial abarca todas as condições apontadas anteriormente, que correspondem, cada uma, a uma variável apresentada no modelo teórico. 


\section{3- RELATO DA EXPERIÊNCIA}

A experiência relatada a seguir foi construída ao longo da experiência profissional, com a preciosa colaboração dos alunos e professores, em numerosos encontros e desencontros. Ao longo dos semestres, os procedimentos sofrem aperfeiçoamentos, em função da revisão das falhas e das críticas. Trata-se do estabelecimento de regras de convívio em sala de aula, pelo professor, em suas turmas de Filosofia e Ética, em cursos de Administração e Turismo.

\subsection{MOMENTOS DA EXPERIÊNCIA}

Podemos dizer que a estratégia se desenvolveu em cinco momentos, de duração variável, conforme a turma e as condições da experiência.

\section{- Primeiro momento: o estabelecimento de regras}

O contrato é um acordo bilateral cuja validade depende de quatro condições a saber: o consentimento das partes que se obrigam; sua capacidade de contratar, um objeto certo que forme a matéria da obrigação e uma causa lícita na obrigação. Em um primeiro momento, chamamos este contrato de "combinado", quando ele era construído com os alunos. Atualmente, falamos, simplesmente, em regras, visto que, em nossa última experiência, deixamos de dar ao aluno o direito de não aceitá-las. As regras são apresentadas pelo professor e não dependem da concordância do aluno. A sua obediência é uma exigência mínima, visto que a causa é lícita: promover um curso de qualidade com o máximo de aproveitamento.

A apresentação das regras se deu através de uma carta escrita e assinada pelo professor, entregue e lida no primeiro dia de aula, acompanhada do plano de ensino e do cronograma do curso. A carta, de uma página, teve a seguinte estruturação: 


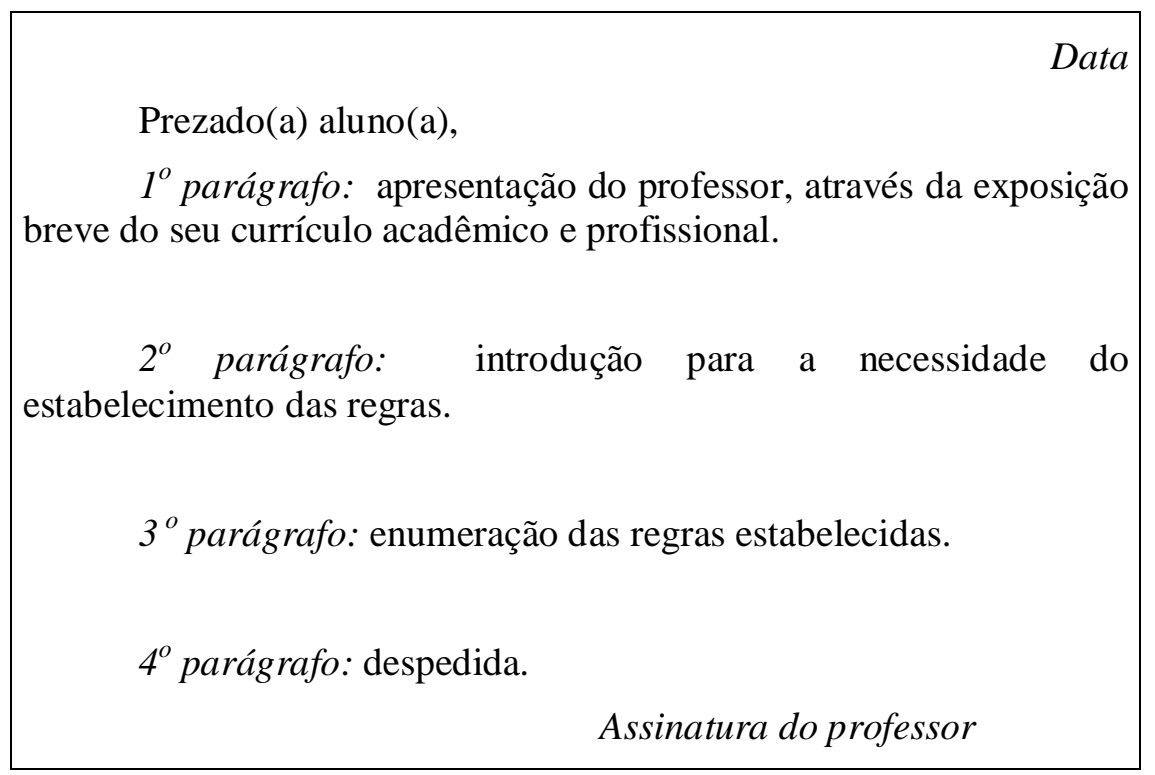

Quadro I: Modelo de carta para a apresentação das regras

A apresentação do professor, conteúdo do primeiro parágrafo, registra o que, geralmente, o próprio professor fala de si mesmo ao apresentar-se para a turma: formação acadêmica, titulação, tempo de serviço na instituição, atividade profissional, principais publicações, etc. Sua colocação no início do artigo não é aleatória. Representa uma primeira medida anti-anti-pedagógica, no sentido de deixar claro que aquele professor tem autoridade para lecionar aquela disciplina.

A introdução para a necessidade do estabelecimento de regras, feita no segundo parágrafo, partiu da explicitação da motivação do professor para o procedimento. Em verdade, a indisciplina, caracterizada pelo entra-e-sai de alunos, o uso indiscriminado do telefone celular e as conversas paralelas foram fatores que não só prejudicavam as aulas, mas também tiravam do professor o seu prazer de lecionar. Abaixo, transcrevemos como este parágrafo foi escrito na última ocasião:

"Sou professor porque gosto. Considero-me responsável por criar e manter um ambiente cordial em sala de aula, que possibilite os diálogos necessários para a aprendizagem da atividade de pensar. O prazer de trabalhar com você depende de algumas condições necessárias para que aproveitemos o tempo e a energia gastos no ofício da educação. Para tal, gostaria de estabelecer algumas regras:"

As regras estabelecidas, enumeradas no terceiro parágrafo, foram as seguintes:

1- "A participação do aluno é sempre bem-vinda. Dela depende o sucesso das aulas.

2- Alunos e professores são responsáveis pela manutenção do clima de respeito e cordialidade entre si.

3- O telefone celular deve ser desligado durante as aulas.

4- As chamadas para verificação da freqüência acontecerão no início de cada aula, observados 30 minutos de tolerância.

5- Depois dos 30 minutos, serão afixados na porta da sala dois avisos de AGUARDE, a saber:

$i$. Um, com os dizeres voltados para o corredor, comunicando que os alunos náo podem entrar na sala. 
ii. Outro, com os dizeres voltados para o interior da sala, comunicando que os alunos não podem sair.

6- Os alunos que não possam assistir à aula devem sair antes da colocação do aviso, ou então aguardar até às 08:20h.

7- Os alunos atrasados, que chegarem depois do aviso afixado devem aguardar até 08:20h., quando o professor vai abrir a porta e permitir que eles entrem. Ao final da aula, estes alunos devem procurar o professor para garantir a presença da segunda aula.

8- Depois das 08:20h., os alunos só poderão sair depois da retirada dos avisos, o que acontecerá quando o tempo da aula estiver esgotado ou quando a matéria do dia estiver concluída Assim os alunos que precisarem sair mais cedo devem fazê-lo neste momento.

9- O aluno é obrigado a trazer o cronograma do curso para a sala de aula, além do seu próprio material (lápis, borracha, caneta, livros, textos, caderno, etc.).

10- Em dia de prova, não é permitido o empréstimo de material, de qualquer espécie.

11- As conversas paralelas devem ser evitadas para não prejudicar o bom andamento das aulas.

12- Não serão aceitos trabalhos depois do prazo estabelecido.

13- A violação destas regras terá a punição de impedir que todos os alunos tenham aulas de qualidade total, que enriqueçam a vida acadêmica, profissional e pessoal de cada um, inclusive do professor.

14- Estas regras podem ser alteradas ou revogadas pelo professor, quando se fizer necessário.

15- Eventual tolerância a alguma destas regras não representa a rescisão das normas estabelecidas."

Tais regras procuraram observar as variáveis descritas no referencial teórico. A variável ética está presente quando se incentiva o respeito, a cordialidade e a participação entre todos, em busca da realização de um valor que é a aprendizagem com qualidade. Também está presente quando se reconhece que a iniciativa do professor e o modo como ela foi feita promovem uma infantilização do aluno, em um primeiro momento. $\mathrm{O}$ aluno recebe passivamente um conjunto de regras sem ser ouvido. Tal estímulo provoca respostas diferentes dos alunos em função do nível de moralidade em que cada um esteja. Os indivíduos fixados na moralidade infantil reagirão conforme o momento evolutivo, seja calando-se por não entender nada, seja se submetendo às regras por medo, seja questionando as regras por vontade de se impor à autoridade, seja fingindo que concordam para agradar o mestre, seja avaliando se a estratégia realmente vai funcionar na prática. Os indivíduos fixados na moralidade adolescente, farão questionamentos recorrendo a explicações abstratas calcadas em valores, como liberdade, ou aceitarão as regras como um modo pacifista de lidar com a situação, considerando que isso representa uma aceitação da liberdade do professor de dar aulas como ele bem entender. As pessoas de moralidade adulta reconhecerão a autoridade e o papel do professor e buscarão avaliar se as regras fazem sentido para si mesmas e terão a malícia de esperar o momento adequado de se posicionarem.

A variável educativa está subliminarmente presente, visto que a passagem do mundo da natureza para a cultura só se faz através do contrato social, do trabalho, da proibição do incesto, do estabelecimento de limites para a convivência, da educação. A variável política está presente à medida que o estabelecimento de regras reconhece que o espaço da sala de aula é um espaço político, arena de interesses, o que exige o contrato e estabelecimento de direitos e deveres. A variável psicológica está presente à medida que o conjunto destas medidas vai exigir do professor absoluta autonomia e consciência do que está fazendo para suportar as inevitáveis ponderações dos alunos no sentido de buscarem fugir do trabalho de estudar. A variável tecnológica está presente à medida que o professor reconhece nesse instrumento um meio de promover o clima adequado para a aprendizagem. Concretamente, faz-se presente através da proibição do uso do telefone celular, norma da instituição, apesar de pouco respeitada na prática. A variável gerencial está presente na totalidade do procedimento, visto que o regulamento é peça fundamental para o exercício da administração e visto que o professor é o líder que detém a autoridade para fazer com que seja 
cumprido. Segundo Arruda e Navram (2000), quanto mais explícitas forem as expectativas e exigências que a organização tem para com seus empregados, maior a motivação dos empregados para ir ao encontro das exigências da organização, visando alcançar o sucesso. As pessoas "necessitam conhecer as posições, os padrões éticos da empresa e o que é considerado uma conduta correta dos funcionários num amplo espectro de situações com as quais poderão defrontar" (ARRUDA e NAVRAN, 2000, p. 32). "Uma das principais razões para que exista a gerencia é para que as regras sejam comunicadas e reforçadas numa empresa" (idem, ibidem).

Os horários estabelecidos nas regras variam de turma para turma. Como as aulas são geminadas e têm a duração de 50 minutos cada, estabeleceu-se que o horário para que os que se atrasarem mais de 30 minutos e aqueles que quisessem sair de sala mais cedo seria exatamente na metade dos 100 minutos de duração da aula.

O último parágrafo é a despedida. Trata-se do desfecho da carta e foi assim elaborado:

"Certo de sua adesão a este conjunto de procedimentos, desejo a todos um excelente semestre letivo, e lembro a frase de um filósofo célebre, chamado Kant: 'Não se pode ensinar Filosofia; pode-se, apenas, ensinar a filosofar'”.

O objetivo da despedida é encerrar a carta. Alguma relação com a matéria do professor é recomendável, através, por exemplo, da citação de uma frase de um autor relevante naquele campo do conhecimento.

\section{- Segundo momento: a teorização sobre o conjunto de regras.}

$\mathrm{O}$ estabelecimento das regras provoca as mais variadas reações da turma. O professor manteve-se firme, escutou eventuais sugestões e, eventualmente, adaptou um ou outro artigo, desde que o espírito das regras não fosse comprometido, qual seja, permitir que o professor e os alunos tivesse um ambiente adequado para a aprendizagem e os debates. Na disciplina de Filosofia e Ética é possível, com o desenvolvimento do conteúdo programático, ir explicando a fundamentação teórica do procedimento de estabelecimento das regras. Como a primeira unidade do curso trata da relação entre Natureza e Cultura, pode-se trabalhar o conteúdo da variável educativa, que fundamentou a experiência, em profundidade, ilustrando-a com a experiência das regras, exigência básica para a construção da cultura.

Em outras disciplinas, o professor pode fazer relações semelhantes. Para isso ele deve verificar se existe relação entre a fundamentação teórica apresentada neste trabalho com o conteúdo programático da sua disciplina.

\section{- Terceiro momento: a reflexão sobre a necessidade do controle externo para a boa convivência em grupo versus a questão da autonomia}

A partir do terceiro mês do semestre, os alunos se mostraram totalmente adaptados às regras, à placa com o aviso de "aguarde", sem nenhum questionamento dos procedimentos introduzidos pelo professor. Quando isso acontece, reconhecemos que a ordem está estabelecida, isto é, não há contexto de crise. Nesse momento, o professor iniciou a reflexão sobre a necessidade do controle externo para que a boa convivência. Eventualmente, desprezou a colocação da placa na porta e verificou se isso facilitava o relaxamento da observância das regras pelos alunos nas aulas seguintes. Quando não foi mais necessária a colocação da placa, o professor promoveu a reflexão sobre a necessidade de um chefe, em um contexto de crise, impor a sua autoridade e, de alguma 
forma, infantilizar os seus subordinados, como ele havia feito em sala de aula. Neste momento, os alunos estudavam a filosofia política de Maquiavel e puderam assim correlacionar a matéria com a função gerencial.

Em uma turma, houve a necessidade de voltar a usar a placa de aguarde. Em outras, as aulas transcorreram sem incidentes de indisciplina.

\section{- Quarto momento: a retirada do papel de autoridade}

Se os alunos passam a respeitar a norma sem a necessidade de controle por parte do professor, está no momento de retirar a sua autoridade e tratar seus alunos como adultos. Isso aconteceu no último mês do semestre. O professor disse que as normas continuavam valendo, mas que ele não mais seria o seu guardião. A partir daquele momento, o professor deixou de fazer as chamadas para demonstrar que não haveria por parte dele o controle. Cada um já deveria saber o que estava fazendo em uma faculdade. Observou-se que alguns alunos faltavam às aulas, mas, no geral, as aulas transcorreram sem problemas de disciplina e com ótimo aproveitamento do tempo das aulas e boa qualidade das mesmas.

\section{- Quinto momento: avaliação}

Antes da prova final, o professor fez uma avaliação da disciplina e do professor. Segundo os alunos, a primeira impressão foi estranha, pois o professor pareceu autoritário. Alguns manifestaram a preocupação, diante do questionamento dos alunos, do professor não levar adiante a idéia, que lhes pareceu muito boa, pois eles se sentiam decepcionados com o ambiente da sala de aula, em que os alunos entram e saem da sala com freqüência, os telefones não param de tocar (principalmente no turno da noite). Os alunos sugeriram que esse procedimento fosse adotado por todos os professores. Alguns chegaram a pedir à coordenadora do curso que isso fosse feito.

\subsection{RESULTADOS DA EXPERIÊNCIA}

Podemos considerar que a experiência foi bem sucedida. Em uma das turmas em que ela foi aplicada, havia problemas de indisciplina em todas as matérias, exceto na matéria de Filosofia e Ética, em que se estabeleceram as regras objeto deste artigo. A coordenadora do curso de Turismo solicitou ao professor que apresentasse a sua experiência e os seus resultados para os outros professores, em reunião, o que motivou a elaboração deste artigo. Nas turmas em que foi utilizada a estratégia, o problema da indisciplina foi reduzido a algo próximo de zero.

$\mathrm{Na}$ avaliação do corpo docente, feita pela Faculdade com os alunos, o professor foi considerado excelente, ficando o seu escore entre os melhores da Faculdade.

\section{4- CONCLUSÕES E RECOMENDAÇÕES}

A primeira conclusão do pesquisador é que os alunos querem aprender mais. Os bons alunos se queixam daqueles que não se comprometem com o ensino e que prejudicam os que querem participar das aulas mais profundamente. A escola precisa dar mais importância aos bons alunos. Como a indisciplina faz mais barulho do que o comprometimento dos alunos, é importante neutralizar a atuação daqueles que impedem ou prejudicam a qualidade das aulas. 
Em segundo lugar, reconhecemos que o professor, em tese, tem mais poder do que os alunos para manter a disciplina em sala de aula, porque tem mais autoridade. É claro que se trata de um papel, que chamamos de função gerencial. Não se trata de superioridade. É seu papel administrar os conflitos em sala. Furtar-se a esse papel e atribuir a responsabilidade apenas aos alunos, que "não querem saber de nada", é renunciar ao papel de gerente da sala de aula, atribuição interdisciplinar que reúne capacidades pessoais, técnicas e políticas.

Em terceiro lugar, é preciso aventar a hipótese de que a matéria do professor - Filosofia e Ética - e o fato dela estar locada no primeiro e no segundo períodos do curso de Turismo e Administração, respectivamente, tenham ajudado no sucesso do empreendimento. $\mathrm{Na}$ reunião de professores para discussão da estratégia, um professor atribuiu parte do sucesso ao fato do professor ser um psicólogo. Entretanto, consideramos que se trata de uma função eminentemente gerencial. Se um professor não é capaz de gerenciar uma sala de aula, como será capaz de gerenciar uma empresa?

Em quarto lugar, é importante salientar que o sucesso do empreendimento depende de requisitos institucionais. A escola, através da coordenação do curso, precisa estar de acordo com o procedimento e dar-lhe sustentação, se necessário for. Em uma das turmas, quando um aluno enfrentou o professor, este requisito mostrou-se fundamental. Depois da aula em que foi feita a apresentação das regras, no primeiro dia letivo, um aluno do curso de Administração disse ao professor, na frente dos colegas, que não concordava com aquelas regras, pois pagava a escola e tinha direito de sair e entrar da sala quando quisesse. Argumentou, de modo agressivo, que trabalhava o dia inteiro, pagava a faculdade do próprio bolso e não achava justo ter que esperar fora de sala, caso se atrasasse por causa do serviço. Disse que o problema do entra-e-sai era do professor, não dos alunos, e que o professor deveria buscar resolver o seu incômodo com este comportamento dos alunos por conta própria. Disse também que procuraria o Diretor e até advogados se alguém o proibisse de assistir às aulas pelas quais pagou. $\mathrm{O}$ professor disse ao aluno, que ele estava desrespeitando-o, que ele iria ter problemas e que ele estava equivocado. $\mathrm{O}$ caso foi comunicado pelo professor ao Coordenador do Curso de Administração, que disse que, caso o problema não fosse resolvido na próxima aula, que ele estava à disposição para procurar o aluno e adverti-lo formalmente. Antes da aula seguinte, alguns alunos procuraram o professor para manifestar que não concordavam com a atitude do colega e para dizer que temiam que o professor voltasse atrás, o que prejudicaria todos os que querem aulas boas e produtivas. Ao fim da aula seguinte, o professor procurou o aluno e lhe disse que ele, o aluno, havia desrespeitado o professor, o que não seria mais admitido, e disse que esta advertência correspondia a uma advertência verbal nos termos do Regimento da escola. A próxima seria uma advertência por escrito. $\mathrm{O}$ aluno desculpou-se e não mais trouxe problemas. Como vimos nesse caso, o apoio institucional, na figura do Coordenador de Curso foi fundamental.

Finalmente, podemos concluir que o problema da disciplina, embora tenha raízes que extrapolam a sala de aula, pode ser administrado pela função gerencial exercida pelo professor que se pretende educador.

\section{5- REFERÊNCIAS BIBLIOGRÁFICAS}

ALVES, Rubens. O que é religião. 13.ed. São Paulo: Brasiliense, 1990.

ARENDT, Hannah. A condição humana. 5 ed. Rio de Janeiro: Forense Universitária, 1991.

ARIÈS, P., DUBY, G. História da vida privada. São Paulo: Companhia das Letras, 1992. v.5

ARRUDA, M. C. C., NAVRAN, F. Indicadores de clima ético nas empresas. Revista de 
Administração de Empresas. v.40, n.3, p.26-35. jul-set. 2000.

BRASIL, M. A. S. Da teoria psicoterapêutica esotérica. 6.ed. Belo Horizonte: Cenpe, 1996.

CROZIER, M. O fenômeno burocrático. Brasília: UnB, 1981.

CUNHA, A. G. Dicionário Etimológico Nova Fronteira da Língua Portuguesa. 2.ed. rev. amp. Rio de Janeiro: Nova Fronteira, 1999.

GOMES, João Carlos Lino. Ética, Poder e Política em Maquiavel. Revista Síntese, Belo Horizonte, v.20, n.60, p.79-91, jan-mar, 1993.

GUERRA, E. L. A. et alli. O problema da indisciplina em sala de aula. In: Momentos: idéias e debates. Informativo técnico, Belo Horizonte, n. 3, jan,1997.

HOUISS, A. Dicionário Houaiss da Língua Portuguesa. São Paulo: Objetiva, 2001.

MAQUIAVEL, N. O Príncipe. Rio de Janeiro: Civilização Brasileira, 1993.

PENA, R. P. M. Ética e felicidade. 3.ed. Belo Horizonte: Fead, 2000.

RIOS, Terezinha A. Ética e competência. São Paulo: Cortez, 1993.

ROJAS, E. O homem moderno: a luta contra o vazio. São Paulo: Mandarim, 1996.

SANTOS, Maria Neves dos. Disciplina: problema seu? Do aluno? Disciplina e responsabilidade. Revista Pedagógica, ano VII, n. 42, nov-dez., 1989.

SIQUEIRA, Moema Miranda et alli. Gerenciando o poder nas organizações. In: ENCONTRO NACIONAL DOS CURSOS DE GRADUAÇÃO EM ADMINISTRAÇÃO, 3, 1992, Belo Horizonte. Anais... Belo Horizonte: Associação Nacional dos Cursos de Graduação em Administração, 1992, p.45. 